\title{
Resolving the Do/Do Not Debate: Communication Perspective to Enhance Sustainable Lifestyles
}

\author{
Donghee N. Lee ${ }^{1, *}$, Myiah J. Hutchens ${ }^{2}$ and Janice L. Krieger ${ }^{3,4}$
}

1 Division of Preventive and Behavioral Medicine, Department of Population and Quantitative Health Sciences, University of Massachusetts Medical School, Worcester, MA 01605, USA

2 Department of Public Relations, College of Journalism and Communications, University of Florida, Gainesville, FL 32611, USA; myiahhutchens@ufl.edu

3 STEM Translational Communication Center, University of Florida, Gainesville, FL 32611, USA; janicekrieger@ufl.edu

4 Department of Health Outcomes \& Biomedical Informatics, University of Florida, Gainesville, FL 32610, USA

* Correspondence: Donghee.Lee10@umassmed.edu

check for updates

Citation: Lee, D.N.; Hutchens, M.J.; Krieger, J.L. Resolving the Do/Do Not Debate: Communication Perspective to Enhance Sustainable Lifestyles. Sustainability 2022, 14, 796. https://doi.org/10.3390/su14020796

Academic Editor: Genovaite Liobikienè

Received: 19 November 2021

Accepted: 7 January 2022

Published: 11 January 2022

Publisher's Note: MDPI stays neutral with regard to jurisdictional claims in published maps and institutional affiliations.

Copyright: (C) 2022 by the authors. Licensee MDPI, Basel, Switzerland. This article is an open access article distributed under the terms and conditions of the Creative Commons Attribution (CC BY) license (https:// creativecommons.org/licenses/by/ $4.0 /)$.

\begin{abstract}
Clear and memorable environmental messaging has been scarce. Recycling contamination is an urgent environmental concern because the public is confused about which items can and cannot be recycled. Environmental campaigns utilizing message framing, a method used to emphasize either the benefits of performing or loss of avoiding an action, may help combat this problem. We conducted an online study $(n=1199)$ and randomly assigned participants to view positively or negatively framed (do vs. do not) messages. Results revealed that participants who viewed negative messages with do not descriptors increased recycling intention, mediated by increased recycling contamination knowledge and recycling efficacy (95\% CI: 0.03, 0.08). The findings suggest that recycling instructions may be more effective when messages are framed negatively using inhibitive descriptors. Results of this study can inform development of environmental campaigns to improve sustainable lifestyles.
\end{abstract}

Keywords: recycling contamination; RCT; science communication; message framing; prospect theory

\section{Introduction}

Recycling contamination is a global environmental and economic threat that accounts for up to 25 percent of materials in recycling facilities in the U.S. alone [1]. Contamination occurs when residents place non-recyclable materials in recycling bins. Contamination not only impedes operation of the recycling facilities, but also increases incineration and the volume of landfill waste by damaging other recyclable goods [2]. Therefore, it is necessary to communicate about recycling in ways that are easily remembered and usable. A wide array of national and statewide initiatives in the U.S., such as "Let's Recycle Right!" by Recycle Across America, "I want to be recycled" by Keep America Beautiful, and Florida Department of Environmental Protection's "rethink, reset, recycle" campaigns, focus on increasing recycling participation while reducing contamination. However, it is unknown whether and how much these messages can foster accurate recycling behavior.

Despite the increased focus on recycling campaigns, communicating about recycling involves challenges. Most recycling messages largely employ an information-deficit approach, in which sustainability campaign managers believe that knowledge is sufficient to change behaviors. While being aware of information is associated with higher participation [3], the relationship between knowledge and actual recycling behavior [4], or frequency of recycling [5] remains inconclusive. In fact, polls show that many people want to recycle; approximately half of American adults recycle whenever possible, and more than 60 percent of adults who self-identify as environmentally conscious reported that they are bothered when other people do not recycle [6]. This environmental consciousness and preference for recycling stands in contrast to the high contamination rate. This suggests 
that the public is ill-informed on how to properly recycle. Therefore, the apparent gap between knowledge and behavior suggests that how recycling information is currently communicated needs to be improved, especially because recycling is widely perceived as confusing even among recyclers [7]. Therefore, strategic messaging is needed to resolve the contamination problem, without compromising the overall intention to recycle.

How communication is structured is one factor that may influence how individuals take action regarding environmentally responsible behaviors [8]. A message with 'a plan of action' is necessary to ensure correct behavior including environmentally conscious individuals [9] because clearly stating anticipated behaviors and consequences can help the audience visualize the impact of their action [10]. One way to increase persuasiveness of the recycling instruction message is by using message framing, a message construction method using positive (gain) and negative (loss) tones to describe an issue of interest [11] To meet this need, the current study conducted an online message experiment using a completely randomized design to examine the cognitive and behavioral effect of gain and loss message framing in the context of recycling and contamination.

Effectively communicating about recycling and contamination requires understanding the dominant portrayal of recycling in environmental messages. Recycling has been typically communicated from a behavioral economics perspective, such that recycling is an environmental gain and failure to recycle as an environmental loss [11-14]. However, conflicting evidence regarding persuasiveness of gain and loss frames pose a challenge for the environmental scholarship and practitioners to appropriately communicate their goals and needs. Thus, the current study examines message framing, the cognitive and psychological effect associated with framing type, and behavioral intention.

This paper is divided into different sections: first, the literature review, in which we put forward the hypotheses and explain the theoretical model; second, the methodology, in which we describe the participants and the procedure; third, the results, in which we describe the results of hypotheses testing; fourth, the discussion, in which we provide theoretical and practical implications of our findings; finally, the conclusion, in which we summarize the key findings and directions for future research.

\subsection{Literature Review}

\subsubsection{Message Framing}

Message framing can influence how persuasive messages shape individuals' attitudes and intentions toward a behavior [15]. Prospect theory [16] posits that individuals make decisions based on the respective risks and uncertainty of outcomes associated with each choice. The theory has influenced the construction of persuasive message designs, specifically for the gain and loss framework. In health message contexts, gain-framed messages emphasize the benefits of adopting the advocated idea, while loss-framed messages emphasize the disadvantages of forgoing the idea. Typically, recycling has been considered as a gain for the environment and not recycling as a loss for the environment [11-14].

However, the effect of message framing is inconsistent; gain-framed messages are more persuasive in some situations, while loss-framed messages are more effective at other times. Message framing employs an argument, consisting of an "if-then" statement with an antecedent (if) involving an action and a consequent (then) consisting of an outcome [17]. Because gain and loss frames focus on the presence or absence of an outcome, the effect of gain and loss-framed message is highly dependent on contexts (e.g., temporal distance, construal level) [18] and audience characteristics (e.g., involvement level, behavioral orientation, need for cognition) [11]. For example, recycling messages could produce positive attitudes when the information is simultaneously written specifically and negatively (e.g., "By not participating ... we waste over 60,000 tons of paper ... recycle paper, cardboard, magazines ... ") or abstractly and positively. (e.g., "By participating ... we will save over 60,000 tons of paper ... recycling will save our precious air, land and water resources.") [18]. In another example, gain-framed messages could influence audience's recycling attitudes when the audience is first primed with guilt, compared to loss-framed messages that could 
influence audience's attitudes when the audience is first primed with shame [19]. In an experimental design study about recycling messages, participants showed greater intention to recycle after seeing loss-framed messages emphasizing the negative consequences of not recycling on themselves and others around them (e.g., "By not recycling, you fail to preserve the health ... endanger not only your future, but also the future of your friends, family ... ") compared to gain-framed messages (e.g., "By recycling, you preserve the health ... improve your future") [20]. Other studies showed that individuals with high issue involvement responded with greater receptivity toward negative messages, but those with low issue involvement showed greater receptivity toward positive messages [11]. Therefore, interpretation of messages may vary by individual audiences and contexts in which the message is situated. This limitation poses challenges for disseminating recycling information, as providing individualized message for each household is impractical and may unintentionally discriminate against low-resource regions.

One solution is focusing on the linguistic strategies embedded in message framing. O'Keefe [17] maintains that the main difference in the gain and loss framework resides in the variation of words and phrases of antecedents (e.g., "if you do ... " versus "if you don't ... "). Therefore, careful attention to the linguistic elements allows construction of messages with variable antecedents (i.e., manipulation of action verbs) and constant consequents (i.e., argument or contexts in which the message is situated). One notable recycling message study grounded in prospect theory characterized recycling as a promotion (contribution) and reducing as an avoidance-oriented (restraint) activity. The first message type promoted recycling by framing it as a contribution to the environment, while the latter message type restrained littering to preserve the environment [8]. This study suggests that an appropriate study design for recycling and contamination messages involve framing recycling as a contribution to environmental conservation and contamination as an avoidable act to prevent environmental degradation.

\subsubsection{Recycling Message Framing}

Recycling messages have typically taken a positive framing approach to induce favorable attitudes towards the environment and recycling as well as intentions to perform pro-environmental behavior $[14,21]$. Positive emotions, including joy and satisfaction generated by positive frames, as opposed to fear and anger generated by negative frames [12] which align people's general belief in the environmental benefits of recycling and satisfaction with their decisions to recycle [14]. Additionally, positive frames elicit more favorable attitude toward the message, issue, in turn increasing behavioral intention for issues that convey a sense of urgency and clear personal benefits [21]. Positive framing is especially effective for environmental messages that highlight significance of individual action [22].

Further, an action is driven by intentions to perform a behavior, which is influenced by attitudes and the perceived social norms (e.g., theory of reasoned action and theory of planned behavior). Therefore, positive attitudes toward an issue and a belief that the behavior is a socially acceptable are main motivations for environmental behaviors [12]. However, the effect of positive framing is limited to emotion; despite the positive affect produced by positively framed messages, evidence suggests that negatively framed messages are in fact more effective in increasing the recycling behavior [14]. Therefore, despite the positive feelings induced by positive framing, negatively framing messages can produce an actual, measurable behavioral outcome.

Hypothesis 1 (H1). Compared to positively phrased (do) instructions, negatively phrased (do not) recycling instructions will positively predict recycling intention.

\subsubsection{Cognitive Effect of Negative Framing on Recycling Messages}

Effectiveness of negatively framed messages on fostering intention to adopt a recommended behavior can be explained by negativity bias [12]. Exposure to negative information can heighten individuals' cognition through negativity bias, a phenomenon in 
which negative information is viewed as more important and salient compared to positive information [23], possibly due to discomfort elicited from imagining negative consequences implied in the message [14]. Therefore, providing specific details in negatively written recycling messages can enhance message efficacy [13]. However, audience characteristics may influence the effect of negative framing, as negative framing may reduce perceived efficacy, in turn leading the audience to avoid the message [24]. Specifically, a negatively framed message containing threatening content may reduce the audiences' self-efficacy and a sense of accountability to perform the behavior [12]. In an experimental study regarding climate change, a negatively framed message highlighting the negative consequences of not engaging in a sustainable behavior was more persuasive for audiences with low issue interest, while a positively framed message highlighting the benefits of engaging in a behavior was more persuasive for audiences with high issue interest. [25]. Surprising messages can also improve cognitive processing. Expectancy violation occurs when individuals, who are typically accustomed to seeing positive messages, are exposed to negative information [11]. This is especially relevant for recycling, which has been positively framed as an altruistic, environmentally beneficial behavior $[8,18,19]$. For instance, research found that negatively worded signs (e.g., please do not) were more effective than positively worded signs (e.g., please do) in encouraging tourists to stay on the permitted trail areas [26].

Hypothesis 2 (H2). Compared to positively phrased (do) instructions, negatively phrased (do not) recycling instructions will positively predict contamination knowledge.

\subsubsection{The Mediating Role of Knowledge and Efficacy on Recycling Intention}

Knowledge is one factor that influences behavioral changes regarding recycling [5,7]. Aside from the perceived environmental benefits of recycling, being aware of the municipal recycling programs and policies (i.e., disposal rules, techniques, and waste pick-up schedules) increases recycling intention and behavior [5]. However, individuals' recycling knowledge is generally subjective and incorrect [3]. Efforts to increase correct, objective recycling knowledge is instrumental to reduce contamination. Recycling instructions need not only be specific, but also simple, clear, and understandable [8] because individuals spontaneously dispose materials (i.e., recycling, trashing, or littering) simply based on the appearance [27].

Identifying the direction and goals are important for effective sustainability communication. Specifically, communication of sustainability $(\mathrm{CoS})$ process involves a linear transmission of information, such as education; communication about sustainability (CaS) process involves a participatory discourse involving stakeholders; communication for sustainability (CfS) concerns with a goal, such as societal transformation toward sustainable development [28]. While CaS is an appropriate approach for CfS and achievement of impactful societal changes [28], this approach requires extensive resources and investment. Thus, dialogic approach may be ideal for high-resource regions, yet it may be inappropriate for underserved regions lacking resources to engage their residents to participate in recycling communication [29]. Rather, these regions may benefit from CoS approach to increase knowledge in a short time span and implement the CaS approach in their campaign long-term. As such, our goal is not to encourage a CoS approach for all recycling and sustainability communication, rather provide an option to educate residents when needed.

According to Bandura [30], knowledge is also important for enhancing self-efficacy, which is individuals' beliefs in their own ability to carry out specific activities associated with the behaviors and a key motivator of behavior. Verbal persuasion can influence the degree of self-efficacy by encouraging individuals to exert and sustain efforts to reach their goals. Specifically, when an individual sees information that is unexpected and incongruent with their existing beliefs, they draw on their knowledge to increase self-efficacy prior to making behavioral decisions. Empirical studies found that greater knowledge predicts greater self-efficacy [31], such as individuals with more general health knowledge having higher self-efficacy to perform preventive behaviors [32]. The association of knowledge 
and self-efficacy suggests that individuals' ability to remember information will improve their confidence and belief in their own ability to correctly perform a behavior.

Hypothesis 3 (H3). Increase in contamination knowledge will positively predict recycling efficacy.

Leading behavioral psychology theories (e.g., social cognitive theory and social learning theory) have maintained that self-efficacy is a key predictor of individual behaviors. Specifically, self-efficacy increases individuals' intentions to perform an activity before changing behaviors [33] because individuals with greater perceived efficacy are likely to capitalize on their knowledge to support their action [34]. Individuals with strong selfefficacy are more likely to behave in ways that align with their goals, in contrast to those with lower self-efficacy [30]. Self-efficacy has been associated with healthy behaviors, such as weight loss [35] and cancer screening [36]. In the recycling context, instructions using a negative frame can lead to higher self-efficacy, which in turns leads to greater recycling behavior [13].

Hypothesis 4 (H4). Recycling efficacy will positively predict recycling intention.

Each suggested pathway comprises a broader model to predict recycling intention. This study suggests that negatively phrased messages instructing individuals to not recycle will allow them to remember information better [26]. Next, increased knowledge will lead to a greater efficacy to perform a recommended behavior (i.e., recycling) [31,32]. In turn, increased recycling efficacy will lead to a greater intention to engage in a recycling behavior $[13,33]$.

Hypothesis 5 (H5). Negatively phrased messages will have a positive indirect effect on recycling intention via increased knowledge and efficacy.

\section{Materials and Methods}

\subsection{Procedures}

This study was part of a broader environmental research project that tested various message variation types. Upon the approval of the Institutional Review Board, we used non-probabilistic convenience sampling to recruit total 1199 participants from a Southeastern state from the Qualtrics online panel from 19 March to 26 May 2019. Participants who consented to participate in this study took a baseline contamination knowledge assessment. Afterwards, they were randomly assigned to one of nine message conditions (eight experimental messages and one control without information) and asked to answer a series of questions (see Supplementary Materials). Upon completion of this study, participants were thanked and compensated through Qualtrics. See Table 1 for participant demographics and Figure 1 for the CONSORT diagram illustrating the process.

Table 1. Participants sociodemographic characteristics ${ }^{1}$.

\begin{tabular}{cc}
\hline Characteristics & $n($ SD) \\
\hline Mean \pm SD age years & $34.36 \pm 16.66$ \\
Sex & $306(25.5)$ \\
Male & $884(73.7)$ \\
Female & \\
Race & $23(1.9)$ \\
Asian & $40(3.3)$ \\
American Indian or Alaska Native & $252(21.0)$ \\
Black or African American & $152(12.7)$ \\
Hispanic or Latino &
\end{tabular}


Table 1. Cont.

\begin{tabular}{|c|c|}
\hline Characteristics & $n(\mathrm{SD})$ \\
\hline Native Hawaiian or Pacific Islander & $5(0.4)$ \\
\hline White & $699(58.3)$ \\
\hline Other & $27(2.3)$ \\
\hline \multicolumn{2}{|l|}{ Ethnicity } \\
\hline Hispanic or Latino & $227(18.9)$ \\
\hline Neither & $954(79.6)$ \\
\hline \multicolumn{2}{|l|}{ Education } \\
\hline No schooling completed & $8(0.7)$ \\
\hline Some school, up to 8th grade & $16(1.3)$ \\
\hline Some high school, no diploma & $76(6.3)$ \\
\hline High school graduate, diploma or the & \\
\hline $\begin{array}{l}\text { equivalent } \\
\text { (e.g., GED) }\end{array}$ & $338(28.2)$ \\
\hline Some college credit, but less than 1 year & $163(13.6)$ \\
\hline 1 or more years of college, no degree & $137(11.4)$ \\
\hline Associate degree (e.g., AA, AS) & $128(10.7)$ \\
\hline Bachelor's degree (e.g., BA, AB, BS) & $190(15.8)$ \\
\hline $\begin{array}{c}\text { Master's degree } \\
\text { (e.g., MA, MS, MEng, MEd, MSW, MBA) }\end{array}$ & $99(8.3)$ \\
\hline $\begin{array}{l}\text { Professional degree (e.g., MD, DDS, DVM, LLB, } \\
\text { JD) }\end{array}$ & $25(2.1)$ \\
\hline Doctorate degree (e.g., $\mathrm{PhD}, \mathrm{EdD})$ & $16(1.3)$ \\
\hline \multicolumn{2}{|l|}{ Income } \\
\hline Less than $\$ 20,000$ & $332(27.7)$ \\
\hline$\$ 20,000-\$ 39,999$ & $300(25.0)$ \\
\hline$\$ 40,000-\$ 59,999$ & $214(17.8)$ \\
\hline$\$ 60,000-\$ 79,999$ & $131(10.9)$ \\
\hline$\$ 80,000-\$ 99,999$ & $97(8.1)$ \\
\hline$\$ 100,000-\$ 119,999$ & $46(3.8)$ \\
\hline$\$ 120,000-\$ 139,999$ & $33(2.8)$ \\
\hline More than $\$ 140,000$ & $39(3.3)$ \\
\hline \multicolumn{2}{|l|}{ Rurality } \\
\hline Rural & $379(31.6)$ \\
\hline Urban & $813(67.8)$ \\
\hline
\end{tabular}

${ }^{1}$ Total participants $n=1199$ were recruited from Qualtrics panel.

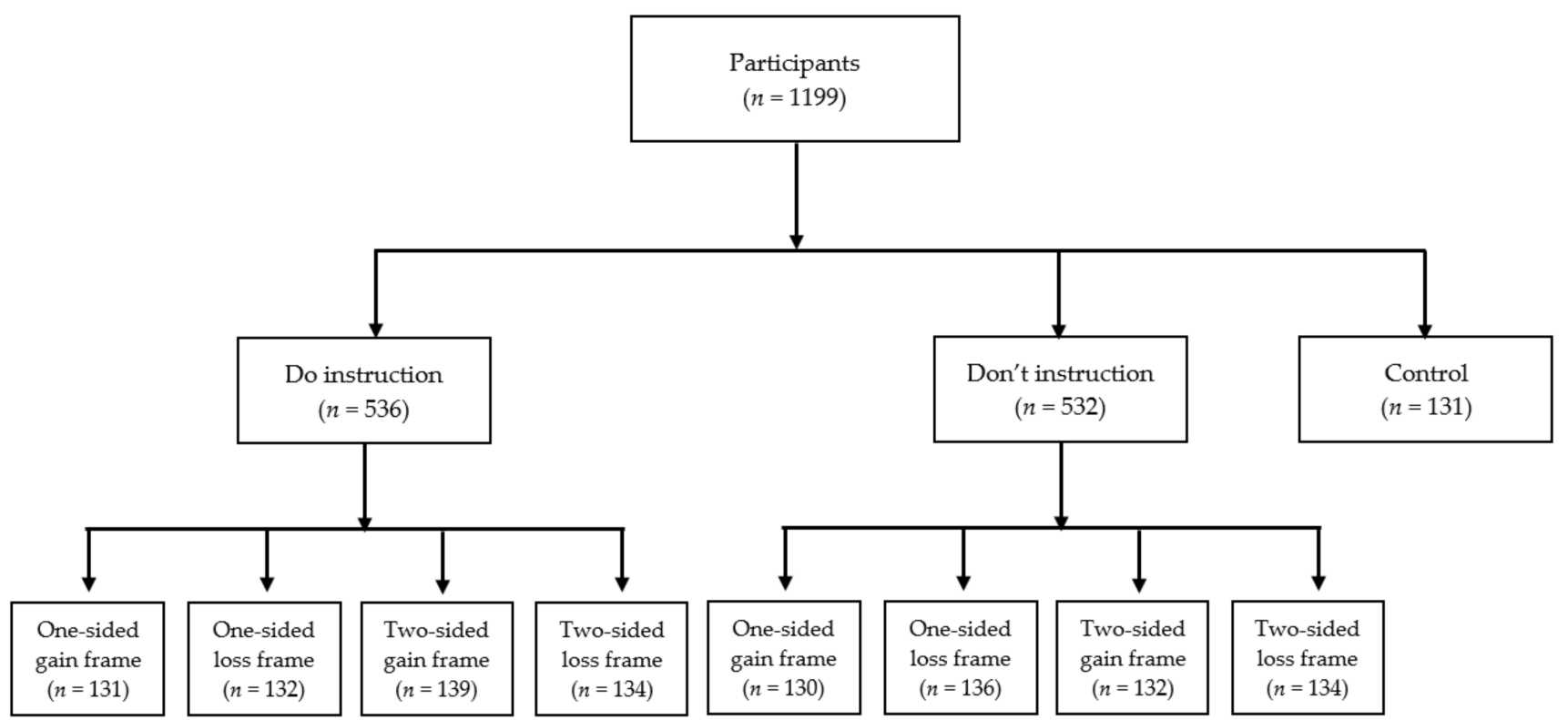

Figure 1. CONSORT diagram illustrating the process of random assignment to stimuli. 


\subsection{Experimental Design}

This study employed a 2 (verb: do/do not) $\times 2$ (framing: gain/loss) $\times 2$ (sidedness: one/two) factorial design experiment with a control group. The development of eight experimental stimuli and the control condition were informed by an infographic of recyclable and non-recyclable items from an online statewide recycling educational resource [37]. For a verbal condition, "do" instructions were written using an action promotive verb ("Recycle ...") and provided a list of materials that should be recycled. Alternatively, "don' $t$ " instructions were written using an action inhibitive verb ("Don't recycle ... ") and provided a list of materials that should not be recycled. Each "do" and "don't" condition comprised of four message variations (one-sided, two-sided, gain-frame, loss-frame). See Supplementary Materials.

\subsection{Manipulation Check}

Participants were asked to indicate their perceived focus of message from five items (e.g., cost/benefit, loss/gains; $\alpha=0.94)[19,38,39]$ on a seven-point bipolar scale. An independent t-test analysis was performed and found that do instructions were rated to have significantly more positive overtone $(M=5.15, S D=1.64)$ than do not instructions $(\mathrm{M}=4.77, \mathrm{SD}=1.78 ; t(1052)=3.59, p<0.001)$.

\subsection{Measures}

\subsubsection{Contamination Knowledge}

Contamination knowledge of participants was measured by asking participants to indicate their recycling knowledge using a twelve-item question (e.g., "Please which of the following items you should recycle-aluminum cans, steel cans, plastic jugs ... " on a seven-point scale ( $1=$ Never 7 = Always $)$ before and after being presented with stimuli. This measure was adapted from the list of recyclable items from a state educational recycling infographic [37]. Six items were recyclable (i.e., aluminum cans, steel cans, plastic bottles, plastic jugs, paper, cardboard) and the other six items were not recyclable (i.e., pizza box, Styrofoam, bubble wraps, plastic bags, hoses, clothing). The items were presented in a randomized order.

The contamination knowledge change score was created by calculating the change in knowledge from the pre- to post knowledge questions. Knowledge scores for the do condition were obtained by subtracting the sum of pre-test scores for recyclable items from the sum of post-test scores of the same items $(\mathrm{M}=5.81, \mathrm{SD}=1.43, \alpha=0.87)$. Likewise, knowledge scores for the do not condition were computed by subtracting the sum of pre-test scores for non-recyclable items from the sum of post-test scores for the same items $(\mathrm{M}=4.07, \mathrm{SD}=2.03, \alpha=0.89)$. Afterwards, the do and do not knowledge scores were combined into one total knowledge scale. The total scores ranged from -2.08 to 3.25 $(\mathrm{M}=0.56, \mathrm{SE}=0.95)$. To reduce priming effect, three items from a news interest scale [40] were asked after the pre-test knowledge questions (e.g., "In general, how much do you enjoy keeping up with the news?" on a seven-point scale, $1=$ Not at all, $7=\mathrm{Alot}) ;(\mathrm{M}=3.70$, $\mathrm{SD}=1.66, \alpha=0.74)$.

\subsubsection{Recycling Efficacy}

Seven items measured total recycling efficacy. Three items from perceived efficacy scale [18] ("I feel that by recycling I can make a difference") $(\mathrm{M}=5.40, \mathrm{SD}=1.54, \alpha=0.85)$, and four items from self-efficacy scale ("How confident are you that you can recycle correctly ... even if you need a long time to develop the necessary routines") were asked on a seven-point Likert scale to measure total efficacy [41] $(\mathrm{M}=5.43, \mathrm{SD}=1.47, \alpha=0.91)$. Due to high correlation between perceived efficacy and self-efficacy $(r=0.71)$, two scales were combined into one scale to measure the overall recycling efficacy $(\mathrm{M}=5.42, \mathrm{SD}=1.39$, $\alpha=0.92$ ). 


\subsubsection{Recycling Intention}

Three items from the recycling intention scale (e.g., "How likely are you to recycle?") were measured on a seven-point Likert scale ( $1=$ Extremely unlikely, $7=$ Extremely likely) [18]. The last item was reverse coded but removed during analysis because it caused a significant drop in the overall recycling intention reliability. The Spearman-Brown split half reliability coefficient between two items was computed $(r=0.87)$.

\subsection{Data Analysis}

All analyses were conducted using SPSS v. 25. First, the effect of the control, do, and do not message conditions on outcome variables was tested using one-way ANOVA. As expected, the control condition was not associated with knowledge. See Table 2. Additionally, differences in the message conditions on efficacy and recycling intention were not significant. (Univariate analysis was performed to test the interactions between verb (do/do not) and frame (gain/loss) conditions on outcome variables (knowledge change, efficacy, recycling intention). We detected no significant differences in the interaction effects on the outcome variables, and thus excluded from further analysis).

Table 2. Unadjusted means for knowledge change in each message condition.

\begin{tabular}{cccc}
\hline Message Conditions & $N$ & M (SD) & 95\% CI \\
\hline Control & 127 & $-0.07(0.52)$ & $-0.16,0.02$ \\
Do instructions & 520 & $0.30(0.78)$ & $0.24,0.37$ \\
Do not instructions & 525 & $0.81(1.03)$ & $0.72,0.89$ \\
\hline
\end{tabular}

Next, Hayes PROCESS Macro. v3.3 (model 6) was used to test the indirect effect of do and do not instructions on recycling intention mediated by knowledge change and efficacy. In this analysis, participants in the control condition $(n=131)$ were excluded as the control condition was not related to knowledge. Participants were evenly split into either the "do" $(50.2 \%)$ or "don't" $(49.8 \%)$ condition.

\section{Results}

\section{Testing Hypotheses}

Hypothesis 1 was not supported. Results indicate that the do instructions directly led to recycling intention. In other words, individuals had greater willingness to participate in recycling after viewing positively written instructions, which promoted them to recycle certain materials, compared to instructions discouraging them from recycling, $b=-0.20$, $S E=0.06, p=0.002,95 \%$ CI $[-0.32,-0.07]$.

Hypothesis 2 was supported. Results indicate that individuals who viewed negatively written instructions inhibiting them from recycling certain items remembered information from the instructions better in comparison to those who viewed positively written instructions that encouraged recycling, $b=0.50, S E=0.06, p<0.001,95 \%$ CI $[0.39,0.61]$.

Hypothesis 3 was supported. Results indicate that individuals who reported greater increase in contamination knowledge were more confident in their ability to do so effectively, $b=0.23, S E=0.05, p<0.001,95 \%$ CI $[0.14,0.32]$.

Hypothesis 4 was supported. Results indicate that recycling efficacy predicted higher recycling intention, $b=0.46, S E=0.02, p<0.001,95 \%$ CI $[0.42,0.51]$.

Hypothesis 5 was supported. Results indicate that indirect effect of negative instructions on recycling intention, mediated by recycling contamination knowledge increase and recycling efficacy, was significant, $b=0.05,95 \%$ CI $[0.03,0.08]$. In essence, seeing negative instructions improved intention to recycle through increased knowledge, which subsequently increases efficacy and then behavioral intentions. Figure 2 provides a visual diagram of the mediation analysis. Table 3 provides statistical details of the mediation model. 
Table 3. Path coefficients from model illustrated in Figure 2.

\begin{tabular}{|c|c|c|c|}
\hline Model Pathways & $b$ & $p$-Value & $\begin{array}{c}\text { Indirect Effect } \\
(95 \% \mathrm{CI})\end{array}$ \\
\hline $\begin{array}{l}\text { Instruction to } \\
\text { knowledge }\end{array}$ & 0.50 & $<0.001$ & $0.39,0.61$ \\
\hline Knowledge to efficacy & 0.23 & $<0.001$ & $0.14,0.32$ \\
\hline $\begin{array}{c}\text { Efficacy to recycling } \\
\text { intention }\end{array}$ & 0.46 & $<0.001$ & $0.42,0.51$ \\
\hline $\begin{array}{l}\text { Instruction to } \\
\text { recycling intention }\end{array}$ & -0.20 & 0.002 & $-0.32,-0.07$ \\
\hline
\end{tabular}

Notes. Mediation analysis conducted using PROCESS macro for SPSS. $b=$ unstandardized beta coefficient; CI $=$ bias-corrected bootstrap confidence interval.

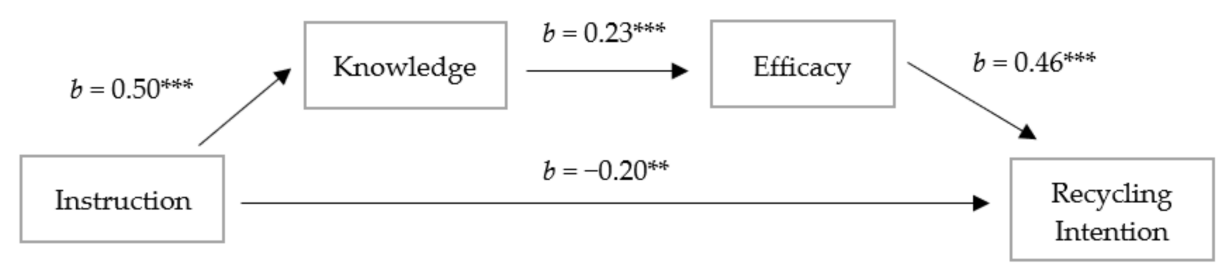

Figure 2. Mediation model illustrating the process of negatively written instructions on causing knowledge, efficacy, and recycling intention. ${ }^{* *} p<0.01$, and ${ }^{* * *} p<0.001$.

\section{Discussion}

The main contribution of this study was to test whether linguistically adapting elements of message framing can help audiences understand the communicated information and influence intention to perform accurate recycling behavior. Message framing rooted in prospect theory [16] currently allows for various audience characteristics and contextual factors (e.g., cites in literature review) that influence the persuasive effect of gain and loss-framed messages. However, various contextual factors limited the application of message framing to broader social issues where providing individualized messages was not practically feasible. This study advances this position by showing how simple adaptation of gain and loss frames can generalize its effect, by characterizing gain frame as a message using a positively phrased instruction with a promoting verb (i.e., do), and characterizing loss frame as a message using a negatively phrased instruction with an inhibitive verb (i.e., do not). Doing this allowed investigating effectiveness of gain and loss-framed messages that is independent of strength of the argument, context, and audience characteristics. Inconsistent with predictions, negatively phrased messages only promoted recycling intention when mediated by increased knowledge and the subsequent increase in self-efficacy. The finding provides further evidence to the claim that a positive and action-oriented message is more effective than a negative, inhibitive message when it does not facilitate critical and active cognitive processing [11].

Evidence of negative messages was observed when predicting knowledge. More specifically, a significant difference between do not and do messages emerged when predicting participants' ability to remember information about recyclable and non-recyclable materials. Subsequently, the ability to remember recycling contamination information enhanced participants' perception of their competence to recycle properly. In turn, participants equipped with knowledge and confidence in their own ability to properly execute a sustainable practice had greater intention to participate in recycling in the future. Taken together, these findings suggest that telling participants what action to avoid was especially effectual than telling them what to do: do not message predicted greater willingness to recycle because this instruction type improved participants' knowledge, which increased efficacy for their own ability to recycle. Importantly, there are still room for improvement; baseline recycling knowledge assessment scores show that participants were more informed about materials that they can recycle, but they were less informed about materials that were not recyclable. The difference in the knowledge type suggests that recycling campaigns 
should place more emphasis on information about unrecyclable materials. In sum, do not message focusing on unrecyclable materials is the most effective and pragmatic approach to enhancing sustainable lifestyles.

The ability of participants to remember information from do not instructions better than do instructions signifies cognitive processing that negative message facilitates. In general, recycling messages have widely framed recycling as an act of environmental contribution and emphasized its broader, societal benefits. Discussion of negative consequences associated with improper disposal behaviors has been scarce until the change of the international solid waste trading policy in 2018, when the Chinese government banned importation of contaminated recyclable, which had the greatest economic impact on primary exporting nations such as the U.S. [42]. From the lay public perspectives, a recycling contamination message might contradict their pre-existing beliefs and cultural norms, which have instilled the value of recycling. It is likely that the expectancy violation resulting from the conflict in values and messages facilitated cognitive processing of participants reading do not instructions [11]. Additionally, inhibitive instructions could have enacted negativity bias [23] by allowing participants to imagine negative consequences of recycling contamination and eliciting discomfort in learning that their well-intended, Good Samaritan act of recycling contributed to environmental destruction [14]. Therefore, enhanced knowledge of do not instructions theoretically corroborates the cognitive effect of negative messages [11].

The second part of the pathway illustrating the role of self-efficacy adds a critical contribution to the science communication literature. While the cognitive finding about do not instructions supports the fundamental role of knowledge, relating this finding to its behavioral effect needs to be interpreted with caution. An exclusive focus on knowledge may perpetuate the idea of information deficit, a predominant belief in the scientific community that simply having information is sufficient for changing behaviors. However, communication based on the deficit approach may result in inappropriate behavioral changes [43]. Inclusion of the role of self-efficacy helps counterargue the claim that information is a sufficient predictor for behavioral change. Rather, knowledge is only effective to the extent that it empowers individuals to capitalize on their knowledge to correctly perform a desired activity [33,34]. Collectively, the evidence presented in this study supports the persuasive effect of message framing and structure in the environmental context.

A major contribution of this study is advancement of a leading behavioral economic theory. This study takes an unprecedented approach to message framing theory by focusing on the linguistic effect of gain and loss-framed message that is independent of audience characteristics and the context in which the message is situated. This approach not only illuminates opportunities for future message framing research, but also allows practical application that is readily implementable in the current recycling and recycling contamination message interventions. Further, findings about the role of knowledge on selfefficacy to recycle support the claim to shift away from the information-deficit approach, but rather consider the implications of knowledge before leading to behavioral changes. Taken together, this study illuminates key areas of the message framing scholarship and opportunities to improve the sustainable lifestyle practices.

From a pragmatic perspective, these findings provide an evidence-based tool to enhance sustainability campaign initiatives and meet specific sustainable goals of each region based on its needs. For example, practitioners aiming to increase recycling participation in their region should frame the message positively and include the list of acceptable materials in the instructions, while those aiming to reduce contamination in their region should frame the message negatively and include the list of forbidden items in the instructions. Findings from this study can be easily integrated into an existing message intervention to enhance message efficacy.

More specifically, the cognitive pathway produced by do not instructions illustrated in this study is useful to address the major contributor of contamination, wish-cycling, which refers to the practice of recycling questionable items in hopes of them being recycled. 
The effect of do not instructions on improving knowledge and self-efficacy, which in turn increases recycling intention, suggests that negatively phrased instructions is an effective solution to close the knowledge and behavior gap. This strategy is especially necessary for recycling, where inaccurate perception about recycling information prevails over objective knowledge across the cultures [3]. The strategy can also benefit environmentally conscious individuals, whose strong motivations for environmental conservation are mistranslated into unintended, adverse effects due to confusing recycling information.

Despite these contributions, this study has limitations that suggest opportunities for future research. A major limitation of this study involves the sample characteristics. The sample mainly consisted of non-Hispanic, white female participants, primarily located in urban areas. In addition, the sample of this study is limited to one state in the United States with high tourist and retiree populations. The unique residential characteristics might have resulted in unparalleled enforcement and communication with residents about recycling policies compared with other areas, causing greater awareness of the current recycling industry climate compared to those in other states. In fact, the state included in this study recently passed a law mandating an increase in recycling participation in a limited time span. This initiative has forced the state and local governments to actively disseminate recycling information and engage the public in the recycling discussions. The random assignment of participants to the experimental conditions controlled for the discrepancy in participant characteristics and confidently established the causality of the do not instructions on knowledge and recycling intention. Future studies should potentially examine how regional differences in recyclable items influence knowledge and behavior regarding recycling. Further, it would be informative for future research to probe message efficacy in respect to residents' pre-existing interest and personal relevance with sustainability issues, which might have affected their attention level and ability to remember the instructions more than those with less interest and relatability. Additionally, although the difference between the do and do not conditions on the manipulation check was small, although statistically significant. While the effect size was small, the finding is meaningful when applied to the general population. Our findings suggest that knowing what not to recyclable is an important tool that practitioners can employ in their future practices. While our study focused on verbal variations, future research should examine other ways to highlight correct sustainability behavior and ways to increase knowledge.

Another opportunity lies in the cognitive effect of do not instructions on higher knowledge recall because of negativity bias and expectancy violation [11]. While the focus of this study was to test the difference in the message framing type, rather than to understand reasons for different cognitive effect associated with each message framing type. Provided the rich scholarly work on negativity bias and expectancy violation, it is logical to conclude that a counterargument against the widespread recycling norm evoked a surprise in audience to pay greater attention to the instructions. While the goal of this study was to test differences between positive and negative wording of recycling instructions, future studies should assess how expectancy toward recycling behavior may differently influence attention and information recall from each message framing type. Therefore, investigating the possible effect of negativity bias and expectancy violation could have provided richer understanding of the effect of do not instructions in the recycling context. Still, our study provides preliminary evidence on the effect of different wording and message framing to inform the development of recycling campaign messages in a cost-effective and cost-saving way. Future studies could incorporate a mixed-methods approach to include qualitative designs, such as interviews, focus groups, or open-ended questions to provide context to explain the effect of do not instructions on knowledge improvement.

\section{Conclusions}

In a society that predominantly portrays recycling as an altruistic behavior, communicating about recycling contamination and discouraging recycling certain materials is a relatively new and challenging task. Further, contamination adds to the unresolved issue 
of communicating about recycling, which is infamously perceived as confusing [7]. The imminent environmental and economic need posed by the international solid waste trading policy makes it imperative to implement strategic ways to communicate about recycling and contamination. Our findings indicate that participants who saw a negatively worded instruction had a greater increase in their contamination knowledge and efficacy, in turn showing greater willingness recycle.

Limitations of this study include the sample characteristics, which could have influenced differences in pre-existing attitudes, knowledge, and practices regarding recycling. Another limitation involves theoretical investigation. It is plausible that do not instructions were more effective because they violated participants' expectancy regarding recycling, which is typically portrayed as altruistic and environmentally beneficial [11-14]. As such, it is possible that do not instructions filled participants' knowledge gap to a greater extent than do instructions by increasing their attention and cognitive processing when reading do not instructions. However, the study design overcomes the limitations, as our random experimental findings allow controlling for the pre-existing sample differences to infer causality of wording and message framing on recycling knowledge and behavior.

Overall, our findings have practical implications that can inform practitioners to enhance communication about recycling policies with their residents. This study provides evidence that specific communication strategies (i.e., wording and message framing) can inform practitioners to enhance their recycling messages to improve their residents' recycling behaviors. Practitioners across regions can adapt our findings into their communication materials to meet their specific rules and resident characteristics. Overall, our findings provide an affordable tool for practitioners to enhance their sustainability messages to meet their recycling and campaign goals and help their residents move toward a sustainable lifestyle. In sum, this study helps advance understanding ways to leverage message framing to facilitate appropriate disposal behaviors without compromising the overall willingness to recycle. More research is needed to develop and test recycling contamination messages to help the public engage in sustainable lifestyles.

Supplementary Materials: The following supporting information can be downloaded at: https: / /www.mdpi.com/article/10.3390/su14020796/s1; File S1-Message Type.

Author Contributions: Conceptualization, D.N.L. and J.L.K.; methodology, D.N.L. and J.L.K.; validation, D.N.L. and M.J.H.; formal analysis, D.N.L.; writing—original draft preparation, D.N.L.; writing-review and editing, M.J.H.; visualization, D.N.L. and M.J.H.; supervision, J.L.K.; project administration, D.N.L.; funding acquisition, J.L.K. All authors have read and agreed to the published version of the manuscript.

Funding: This research was funded by HINKLEY CENTER FOR SOLID AND HAZARDOUS WASTE MANAGEMENT, grant number PRO00017910. Publication of this article was funded in part by the University of Florida Open Access Publishing Fund.

Institutional Review Board Statement: The study was conducted in accordance with the Declaration of Helsinki and approved by the Institutional Review Board (or Ethics Committee) of UNIVERSITY OF FLORIDA (protocol code IRB201900628 and approved on 5 March 2019) for studies involving humans.

Informed Consent Statement: Informed consent was obtained from all subjects involved in the study.

Data Availability Statement: Raw dataset from this study can be accessed: https://doi.org/10.528 1/zenodo.5831950.

Conflicts of Interest: The authors declare no conflict of interest. The funders had no role in the design of the study; in the collection, analyses, or interpretation of data; in the writing of the manuscript, or in the decision to publish the results. 


\section{References}

1. The Dangers of 'Wishcycling'. Available online: http:/ / mediaroom.wm.com/the-dangers-of-wishcycling (accessed on 1 January 2021).

2. Advancing Sustainable Materials Management: 2017 Fact Sheet. Available online: https://www.epa.gov/sites/production/files/ 2019-11/documents/2017_facts_and_figures_fact_sheet_final.pdf (accessed on 1 January 2021).

3. Izagirre-Olaizola, J.; Fernández-Sainz, A.; Vicente-Molina, A. Internal determinants of recycling behaviour by university students: A cross-country comparative analysis. Int. J. Consum. Stud. 2014, 39, 25-34. [CrossRef]

4. McCarty, J.A.; Shrum, L.J. The recycling of solid wastes: Personal values, value orientations, and attitudes about recycling as antecedents of recycling behavior. J. Bus. Res. 1994, 30, 53-62. [CrossRef]

5. Scott, D. Equal opportunity, unequal results: Determinants of household recycling intensity. Environ. Behav. 1999, 31, 267-290. [CrossRef]

6. For Earth Day, Here's How Americans View Environmental Issues. Available online: http:/ www.pewresearch.org/fact-tank/20 17/04/20/for-earth-day-heres-how-americans-view-environmental-issues (accessed on 1 January 2021).

7. De Young, R. Exploring the difference between recyclers and non-recyclers: The role of information. J. Environ. Syst. 1989, 18, 341-351. [CrossRef]

8. Davis, J. The effects of message framing on response to environmental communications. J. Mass Commun. Q. 1995, 77, 285-299. [CrossRef]

9. Rhodes, R.E.; Beauchamp, M.R.; Conner, M.; deBruijn, G.; Latimer-Cheung, A.; Kaushal, N. Are mere instructions enough? Evaluation of four types of messaging on community depot recycling. Resour. Conserv. Recycl. 2014, 90, 1-8. [CrossRef]

10. Jarreau, P.B.; Altinay, Z.; Reynolds, A. Best practices in environmental communication: A case study of Louisiana's coastal crisis. Environ. Commun. 2017, 11, 143-165. [CrossRef]

11. Smith, S.M.; Petty, R.E. Message framing and persuasion: A message processing analysis. Personal. Soc. Psychol. Bull. 1996, 22, 257-268. [CrossRef]

12. Cheng, T.; Woon, D.K.; Lynes, J.K. The use of message framing in the promotion of environmentally sustainable behaviors. Soc. Mark. Q. 2011, 17, 48-62. [CrossRef]

13. Grazzini, P.; Rodrigo, G.; Aiello, G.; Viglia, G. Loss or gain? The role of message framing in hotel guests' recycling behaviour. J. Sustain. Tour. 2018, 26, 1944-1966. [CrossRef]

14. Lord, K.R. Motivating recycling behavior: A quasiexperimental investigation of message and source strategies. Psychol. Mark. 1994, 11, 341-358. [CrossRef]

15. Van de Velde, L.; Verbeke, W. The importance of message framing for providing information about sustainability and environmental aspects of energy. Energy Policy 2010, 38, 5541-5549. [CrossRef]

16. Tversky, A.; Kahneman, D. The framing of decisions and the psychology of choice. Science 1981, 211, 453-457. [CrossRef]

17. O'Keefe, D.J. Message framing variations in health and risk messaging. In Oxford Research Encyclopedia: Communication; Nussbaum, J., Ed.; Oxford University Press: Oxford, UK, 2017.

18. White, K.; MacDonnell, R.; Dahl, D.W. It's the mind-set that matters: The role of construal level and message framing in influencing consumer efficacy and conservation behaviors. J. Mark. Res. 2011, 48, 472-485. [CrossRef]

19. Baek, T.; Yoon, S. Guilt and Shame: Environmental Message Framing Effects. J. Advert. 2017, 46, 440-453. [CrossRef]

20. Loroz, P.S. The interaction of message frames and reference points in prosocial persuasive appeals. Psychol. Mark. 2007, 24, 1001-1023. [CrossRef]

21. Segev, S.; Fernandes, J.; Wang, W. The effects of gain versus loss message framing and point of reference on consumer responses to green advertising. J. Curr. Issues Res. Advert. 2015, 36, 35-51. [CrossRef]

22. Obermiller, C. The baby is sick/the baby is well: A test of environmental communication appeals. J. Advert. 1995, 24, 55-70. [CrossRef]

23. Meyerowitz, B.E.; Chaiken, S. The effect of message framing on breast self-examination attitudes, intentions, and behavior. J. Personal. Soc. Psychol. 1987, 52, 500-510. [CrossRef]

24. Loewenstein, G.F.; Weber, E.U.; Hsee, C.K.; Welch, N. Risk as feelings. Psychol. Bull. 2001, 127, 2-267. [CrossRef]

25. Newman, C.L.; Howlett, E.; Burton, S.; Kozup, J.C.; Heintz Tangari, A. The influence of consumer concern about global climate change on framing effects for environmental sustainability messages. Int. J. Advert. 2012, 31, 511-527. [CrossRef]

26. Winter, P.L. The Impact of Normative Message Types on Off-Trail Hiking. J. Interpret. Res. 2006, 11, 35-52. [CrossRef]

27. Trudel, R.; Argo, J.J. The effect of product size and form distortion on consumer recycling behavior. J. Consum. Res. 2013, 40, 632-643. [CrossRef]

28. Newig, J.; Schulz, D.; Fischer, D.; Hetze, K.; Laws, N.; Lüdecke, G.; Rieckmann, M. Communication Regarding Sustainability: Conceptual Perspectives and Exploration of Societal Subsystems. Sustainability 2013, 5, 2976-2990. [CrossRef]

29. Lee, D.; Krieger, J. Moving from directives toward audience empowerment: A typology of recycling communication strategies of local governments. Sustainability 2020, 12, 2722. [CrossRef]

30. Bandura, A. Self-efficacy. In Encyclopedia of Human Behavior; Ramachaudran, V.S., Ed.; Academic Press: New York, NY, USA, 1994; pp. 71-81.

31. Ievers-Landis, C.E.; Burant, C.; Drotar, D.; Morgan, L.; Trapl, E.S.; Kwoh, C.K. Social support, knowledge, and self-efficacy as correlates of osteoporosis preventive behaviors among preadolescent females. J. Pediatric Psychol. 2003, 28, 335-345. [CrossRef] 
32. Carpenter, V.; Colwell, B. Cancer knowledge, self-efficacy, and cancer screening behaviors among Mexican American women. J. Cancer Educ. 1995, 10, 217-222.

33. Ajzen, I. The theory of planned behavior. Organ. Behav. Hum. Decis. Processes 1991, 50, 179-211. [CrossRef]

34. Bandura, A. Self-efficacy: Toward a unifying theory of behavioral change. Psychol. Rev. 1977, 84, 191-215. [CrossRef]

35. Nezami, B.T.; Lang, W.; Jakicic, J.M.; Davis, K.K.; Polzien, K.; Rickman, A.D.; Hatley, K.E.; Tate, D.F. The effect of self-efficacy on behavior and weight in a behavioral weight-loss intervention. Health Psychol. 2016, 35, 714-722. [CrossRef]

36. Sohler, N.L.; Jerant, A.; Franks, P. Socio-psychological factors in the Expanded Health Belief Model and subsequent colorectal cancer screening. Patient Educ. Couns. 2015, 98, 901-907. [CrossRef] [PubMed]

37. Florida Recycles. Available online: https://floridarecycles.org/ (accessed on 12 December 2021).

38. Lee, A.Y.; Aaker, J.L. Bringing the frame into focus: The influence of regulatory fit on processing fluency and persuasion. J. Personal. Soc. Psychol. 2004, 86, 205-218. [CrossRef]

39. Kao, D.T. Message sidedness in advertising: The moderating roles of need for cognition and time pressure in persuasion. Scand. J. Psychol. 2011, 52, 329-340. [CrossRef] [PubMed]

40. Chyi, H.I.; Lee, A.M. Online news consumption. Digit. J. 2013, 1, 194-211. [CrossRef]

41. Schwarzer, R.; Renner, B. Social-cognitive predictors of health behavior: Action self-efficacy and coping self-efficacy. Health Psychol. 2000, 19, 487-495. [CrossRef] [PubMed]

42. Brooks, A.L.; Wang, S.; Jambeck, J.R. The Chinese import ban and its impact on global plastic waste trade. Sci. Adv. 2018, 4. [CrossRef] [PubMed]

43. Marteau, T.M.; Sowden, A.J.; Armstrong, D. Implementing research findings into practice: Beyond the information deficit model. In Getting Research Findings into Practice, 2nd ed.; Haines, A., Donald, A., Eds.; BMJ Publishing Group: London, UK, 2002; pp. 69-76. 